University of Nebraska - Lincoln

DigitalCommons@University of Nebraska - Lincoln

1988

Studies of the Neural Basis of Evasive Flight Behavior In Response to Acoustic Stimulation in Heliothis zea (Lepidoptera: Noctuidae): Motoneuronal Innervation of Flight Muscles

\author{
Edward Orona \\ Insect Attractants, Behavior, and Basic Biology Research Laboratory, USDA-ARS, Gainesville, Florida 32604 \\ Herndon R. Agee \\ Insect Attractants, Behavior, and Basic Biology Research Laboratory, USDA-ARS, Gainesville, Florida 32604
}

Follow this and additional works at: https://digitalcommons.unl.edu/entomologyother

Part of the Entomology Commons

Orona, Edward and Agee, Herndon R., "Studies of the Neural Basis of Evasive Flight Behavior In Response to Acoustic Stimulation in Heliothis zea (Lepidoptera: Noctuidae): Motoneuronal Innervation of Flight Muscles" (1988). Entomology Papers from Other Sources. 95.

https://digitalcommons.unl.edu/entomologyother/95

This Article is brought to you for free and open access by the Entomology Collections, Miscellaneous at DigitalCommons@University of Nebraska - Lincoln. It has been accepted for inclusion in Entomology Papers from Other Sources by an authorized administrator of DigitalCommons@University of Nebraska - Lincoln. 


\title{
Studies of the Neural Basis of Evasive Flight Behavior in Response to Acoustic Stimulation in Heliothis zea (Lepidoptera: Noctuidae): Motoneuronal Innervation of Flight Muscles
}

\author{
EDWARD ORONA AND HERNDON R. AGEE \\ Insect Attractants, Behavior, and Basic Biology Research Laboratory, \\ USDA-ARS, Gainesville, Florida 32604
}

\begin{abstract}
Ann. Entomol. Soc. Am. 81(6): 986-993 (1988)
ABSTRACT The organization of the motoneurons that control the indirect flight muscles of the fore- and hindwings was investigated in the corn earworm, Heliothis zea (Boddie). Cut axons of the nerves supplying the dorsolongitudinal and dorsoventral muscles were infiltrated with cobalt chloride. The cell bodies of the labeled motoneurons are located throughout all thoracic ganglia. Their respective dendritic fields are organized similarly and distributed in a segmented fashion, i.e., the somata and dendrites are restricted to a rather narrow region of the neuropil. The relevance of this organization for the neural basis of behavior is discussed, focusing on the divergent axonal terminations of primary afferents of the acoustic and mechanoreceptive sensory systems.
\end{abstract}

KEY WORDS Insecta, Heliothis zea, wing innervation, motoneurons

THE AUDITORY SYSTEM of noctuid moths serves well as a model system for studying the neural basis of evasive flight behaviors in insects. Each ear has only a single pair of acoustic cells, the A1 and A2 cells, as well as a nonacoustic B cell (Roeder 1962, 1964). Mapping of the neural circuits involved in the evasive flight behaviors in response to acoustic stimulation will provide a guide to the coding mechanisms of behavioral responses to other sensory modalities. Previous experiments were aimed at understanding the axonal terminations of the acoustic nerves within the thoracic ganglia, so that areas of potential synaptic interaction with the motoneurons that control the flight muscles could be identified (Orona \& Agee 1988, unpublished data).

We investigated the organization within the thoracic ganglia of the motoneurons that control the wing flight muscles in Heliothis zea (Boddie). Because the motoneurons that control the indirect flight muscles are those most involved with evasive flight maneuvers, they represent the final common pathway in the neural circuitry of acoustic stimuli that generates flight. Because it appears that there is a direct monosynaptic connection from one primary acoustic cell (the A2 cell) to the motoneurons, the identification of these motoneurons is of some importance. In addition, second-order acoustic interneurons within the thoracic ganglia (Roeder

This article reports the results of research only. Mention of a proprietary product does not constitute an endorsement or the recommendation for its use by the USDA.
1966, Paul 1974, Boyan \& Fullard 1986) also may contact the motoneurons directly and create additional pathways for coordinated neural control.

\section{Materials and Methods}

The materials and methods used in this paper are presented in our previous paper (Agee \& Orona 1988). All specimens $(n=40)$ were infiltrated with cobalt chloride as described earlier.

Cobalt infiltration was performed on the cut axons of the motor nerves IIN1B, IIIN1A, IIIN1B, and IIINIC. Those nerve trunks to be filled were left at their maximal lengths, whereas all others were cut proximal to the ganglia. All specimens infiltrated with this method were processed through the steps described in the previous paper. The cobalt was precipitated in fresh ammonium sulfide (two drops of $22 \%$ sulfide per $\mathrm{ml}$ of saline) for 10 min. The tissue was then fixed for at least $30 \mathrm{~min}$ in alcoholic Bouin's solution.

Light-microscopic examinations of the thoracic ganglia were made on additional types of preparations. The thoracic cavity and ganglia were stained with either methylene blue, hematoxylin-eosin $(\mathrm{H} / \mathrm{E})$, or HCl Carmine's stain so that the branching of the different nerves and labeling of the different tissues and structures could be observed.

Voucher specimens (slides) will be deposited in the Department of Entomology and Nematology, University of Florida, Gainesville. 

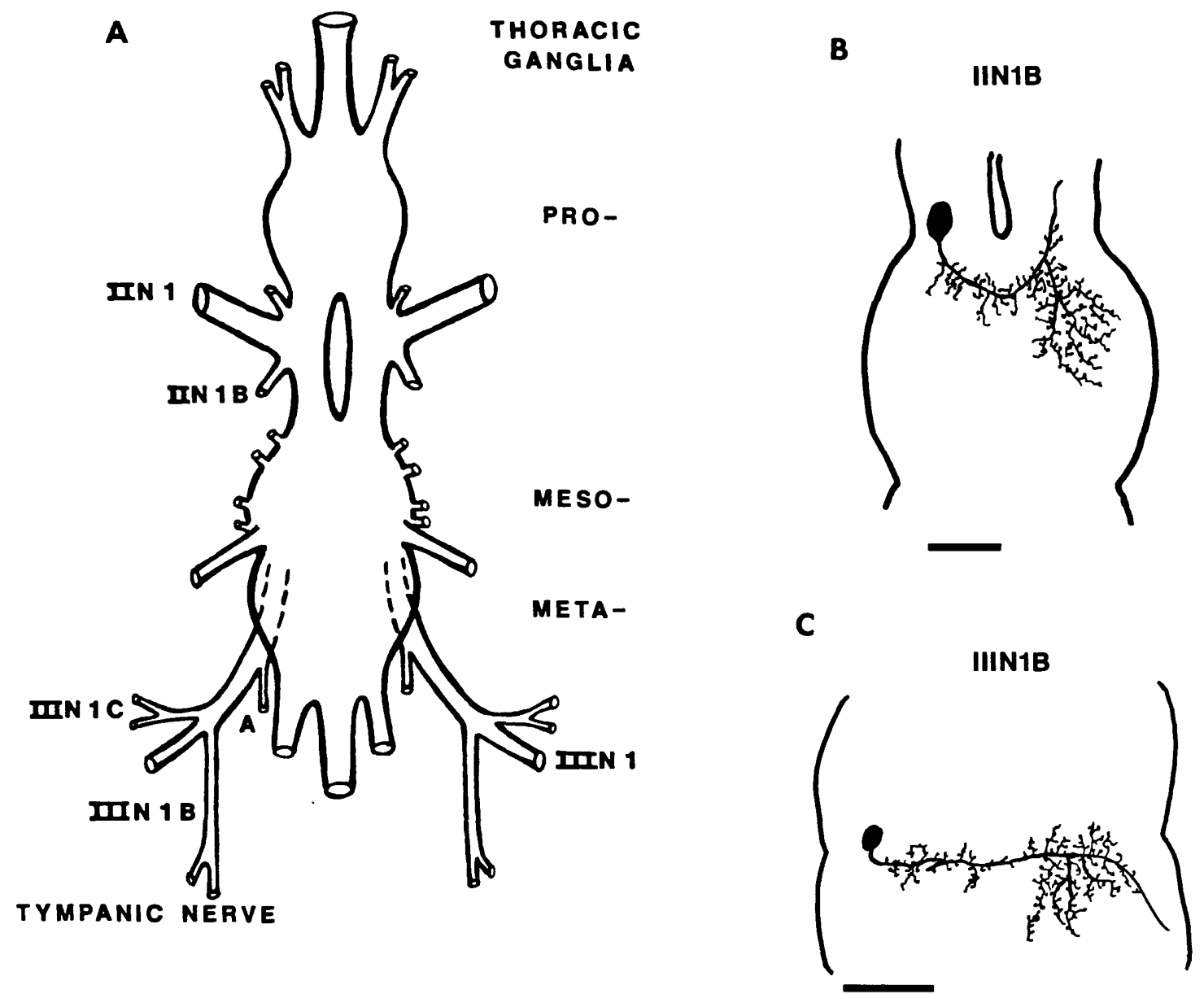

Fig. 1. (A) Schematic drawing of a ventral view of the thoracic ganglia of $H$. zea and the nerves that have been investigated. (B) Camera lucida reconstruction of the contralateral motoneuron of nerve IINlB. The soma is located in the contralateral prothoracic connective and the dendritic field is primarily in the anterior half of the mesothoracic ganglion. (C) Scale drawings of the contralateral motoneuron of nerve IIIN1B, which is located near the fusion of the meso- and metathoracic ganglia. Calibration bar for $(\mathrm{A}, \mathrm{B}, \mathrm{C}) 100 \mu \mathrm{m}$.

\section{Results}

Cell bodies of the motoneurons were found anteriorly and posteriorly in the prothoracic and mesometathoracic ganglia. The labeled motoneurons were associated with several nerves innervating the indirect flight muscles. Nerves IIIN IA and IIIN1C, which innervate the dorsoventral muscles, and nerves IIN1B and IIIN1B, which innervate the dorsolongitudinal muscles, were labeled (Fig. 1).

The general morphology of the motoneurons was uniform. Typically, cell bodies were located either ipsilaterally and ventrally, or contralaterally and dorsally within the ganglion. The general form of a motoneuron consisted of a rather isolated soma with a neurite leading to a large dendritic field or plexus. On any individual motoneuron, the dendritic field was massive and the large number of terminal-like blebs or swellings probably was indicative of a multitude of synaptic inputs.
Infiltration of the nerve branch IIN1B (from the main nerve IIN1 to the forewings) produced labeling in the prothoracic and mesothoracic ganglia (Fig. 2). Ipsilateral to the nerve, six cell bodies were labeled. Four of these cell bodies were large and at the posterolateral edge of the prothoracic ganglion, and two were smaller and situated slightly more anteriorly and laterally. The cell bodies were near the ventral surface, and their respective dendritic fields were dorsal. At least one contralateral cell body was found near the anterior region of the mesothoracic ganglion (actually within the connective to the prothoracic ganglion). Its neurite was at the anterior edge of the mesothoracic, and the dendrites ipsi- and contralateral.

Three of the nerve branches of the main nerve trunk IIINl to the hindwings also were labeled. Branch IIINlA had five ipsilateral cell bodies in the mesothoracic ganglia (Fig. 3). Here again, cell bodies were ventral, and dendritic fields dorsal. 


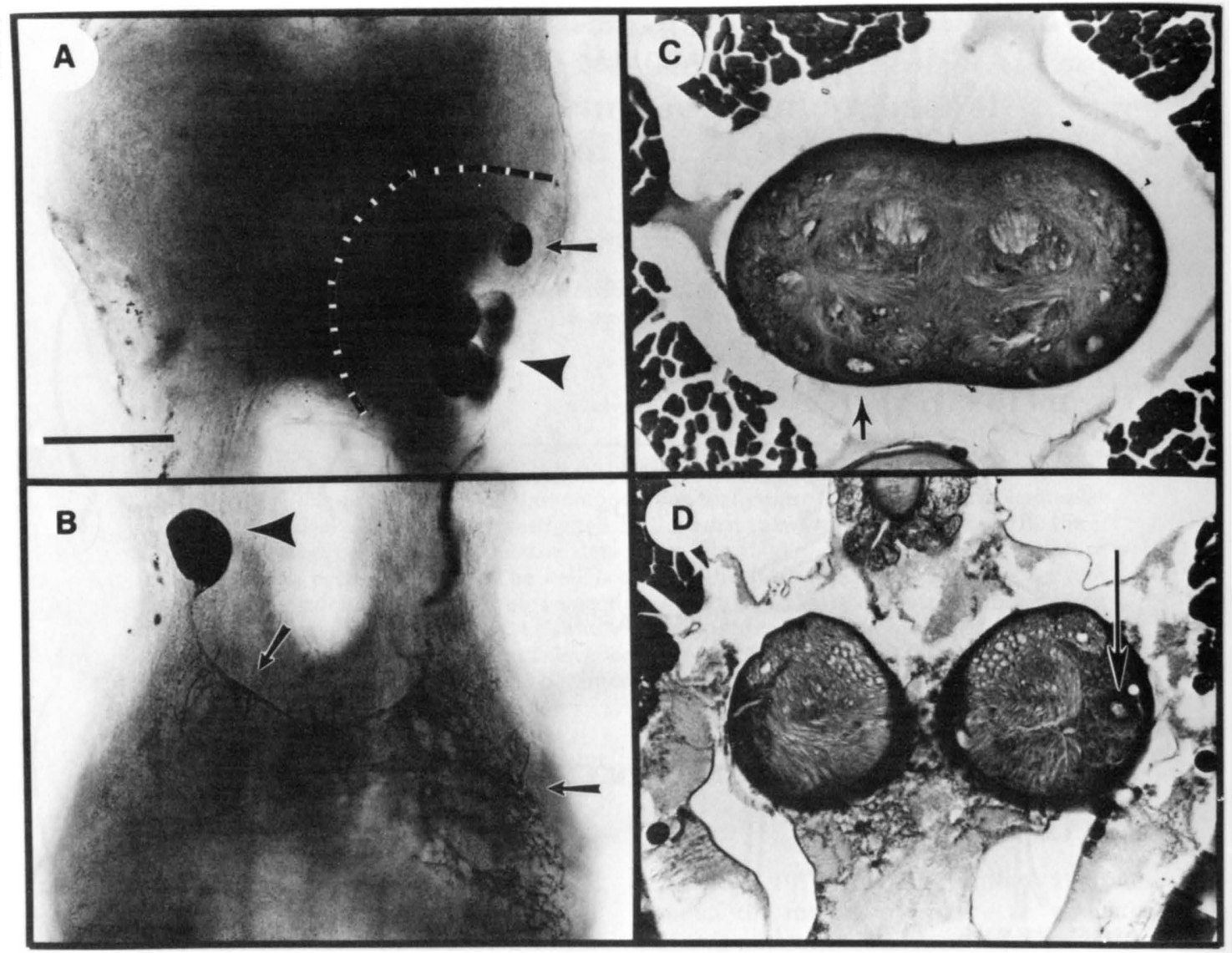

Fig. 2. Photomicrographs of the motoneurons innervating IIN1B. (A) Ventral view of a wholemount cobalt specimen, showing the ipsilateral somata, which occur ventrally in the posterior prothoracic ganglion. Four large cell bodies were labeled (arrowhead) in the corner, and a smaller soma (arrow) was more anterior and lateral. (An additional smaller and medial cell body also is present, but not labeled in this particular specimen.) Dotted line indicates the extent of the cells' dendritic fields that are located dorsally. (B) Ventral view of a wholemount specimen showing the labeling of the ipsilateral cell body (arrowhead). The neurite and dendritic field within the anterior mesothoracic ganglion are indicated by arrows (compare with Fig. 1B). (C-D) Cross-sections of hematoxylin-eosin $(\mathrm{H} / \mathrm{E})$ stained tissue corresponding to $\mathrm{A}$ and $\mathrm{B}$, respectively. The somata of the motoneurons located ventrally are shown by arrows. Calibration bars for $(A, B, C, D) 100 \mu \mathrm{m}$.

One contralateral cell body was found very near the midline, also in the posterior half of the mesothoracic ganglia. The dendritic fields of these motoneurons appeared to overlap somewhat with those of the IIINIB, but the latter were slightly more central and closer to the midline of the mesothoracic ganglia.

Branch IIIN1C was infiltrated, as were its motoneurons in the mesothoracic ganglia (Fig. 4). At least three cell bodies were labeled, two ipsilateral and very near the fusion with the metathoracic ganglion. These two were near the ventral surface, their dendritic fields dorsal within the ganglion. The contralateral cell body was dorsal at the anterior region of the metathoracic ganglia, where it had extensive dendritic branching.

Cobalt infiltration of nerve IIIN1B (Fig. 5) labeled the motoneurons and the tympanic nerve from the ear (unpublished data). Six motoneurons were labeled in the meso-metathoracic ganglia. The cell bodies were in the ventral surface of the ganglia, each with a neurite extending dorsally to a profuse dendritic field. Five of the cell bodies were ipsilateral and in the posterior region of the mesothoracic ganglion. One was contralateral and very close to the region of the fusion of the meso- and metathoracic ganglia. There was dendritic branching off the neurite contralaterally and a large dendritic field in the anterior region of the metathoracic ganglia.

Thus, a variety of motoneurons at several anterior-posterior locations of the thoracic ganglia innervates the indirect flight muscles. In addition to those labeled with cobalt chloride, several other motoneurons left the smaller nerves on the dorsal side of the meso-metathoracic ganglia, and presumably innervated other direct or accessory muscles, or both. These motor nerve trunks were fine in diameter and inserted directly into the muscles. In general, regardless of cell body location, the 


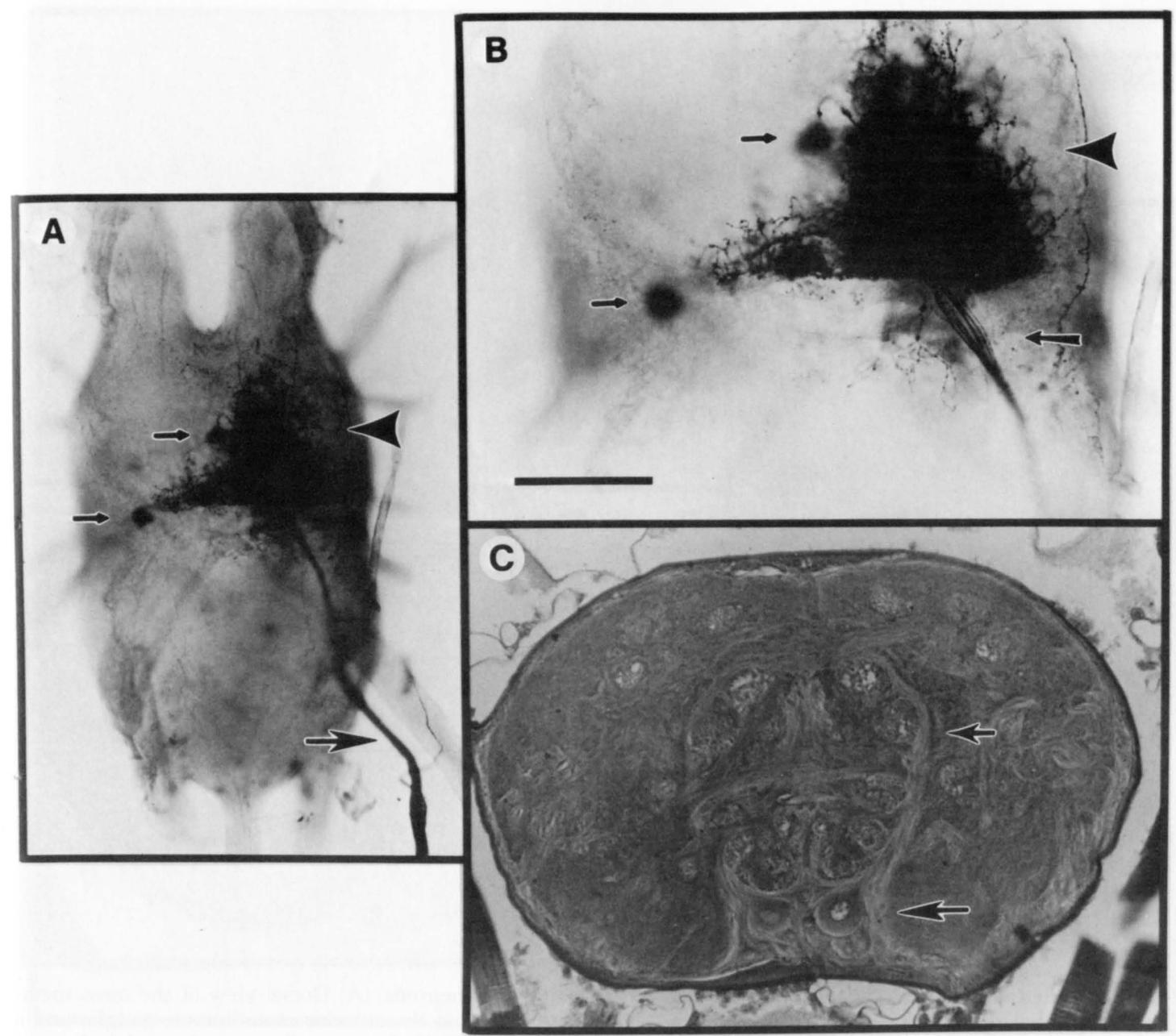

Fig. 3. Photomicrographs of motoneurons innervating IIIN1A. Panels A and B are dorsal views of wholemount cobalt specimens. (A) The large ipsilateral dendritic fields (arrowhead) of the motoneurons occupy the posterior half of the mesothoracic ganglion. Two of the motoneurons (small arrows) are at a different focal depth. Large arrow indicates the nerve IIIN1A exiting the ganglia (compare to Fig. 1A). (B) Higher magnification of the specimen in panel A. Smaller arrows indicate two of the somata. Five axons (large arrow) can be observed leaving the dendritic plexus (arrowhead). (C) An $\mathrm{H} / \mathrm{E}$ stained cross-section of the middle region of the mesothoracic ganglion, showing a midline soma (large arrow) ventrally with its neurite (small arrow) extending dorsally. Calibration bar for (A) $200 \mu \mathrm{m}$; (B, C) $100 \mu \mathrm{m}$.

entire dendritic fields of these motoneurons were confined to a rather small region (ipsi- and/or contralateral) of the neuropil. In addition, all motoneurons emerge from the ganglia at about the same level as their dendritic fields and cell bodies. Hence, there was a segmentation of the motoneuronal fields. These regions include the dorsal areas of the posterolateral prothoracic, anterior and posterior mesothoracic, and the anterior half of the metathoracic ganglia.

\section{Discussion}

A study of the organization of the innervation of the muscles involved in flight control is important because the identification and location of these motoneurons might permit mapping regions of possible synaptic interactions with either primary or interneuronal sensory neurons. The noctuid auditory system is simple and accessible, and thus an excellent model system for studying not only insect audition and sensory coding but also the neuronal basis of evasive flight behaviors (see Agee 1985a,b; Orona \& Agee 1987, 1988).

The motoneurons that innervate the direct and indirect wing flight muscles are scattered throughout the thoracic ganglia in each moth species investigated to date. The direct and indirect muscles that control fore- and hindwing movements are asynchronous (Pringle 1968; Kammer 1971, 1985). Like other investigators, we have focused primarily on the indirect muscles because these are involved 


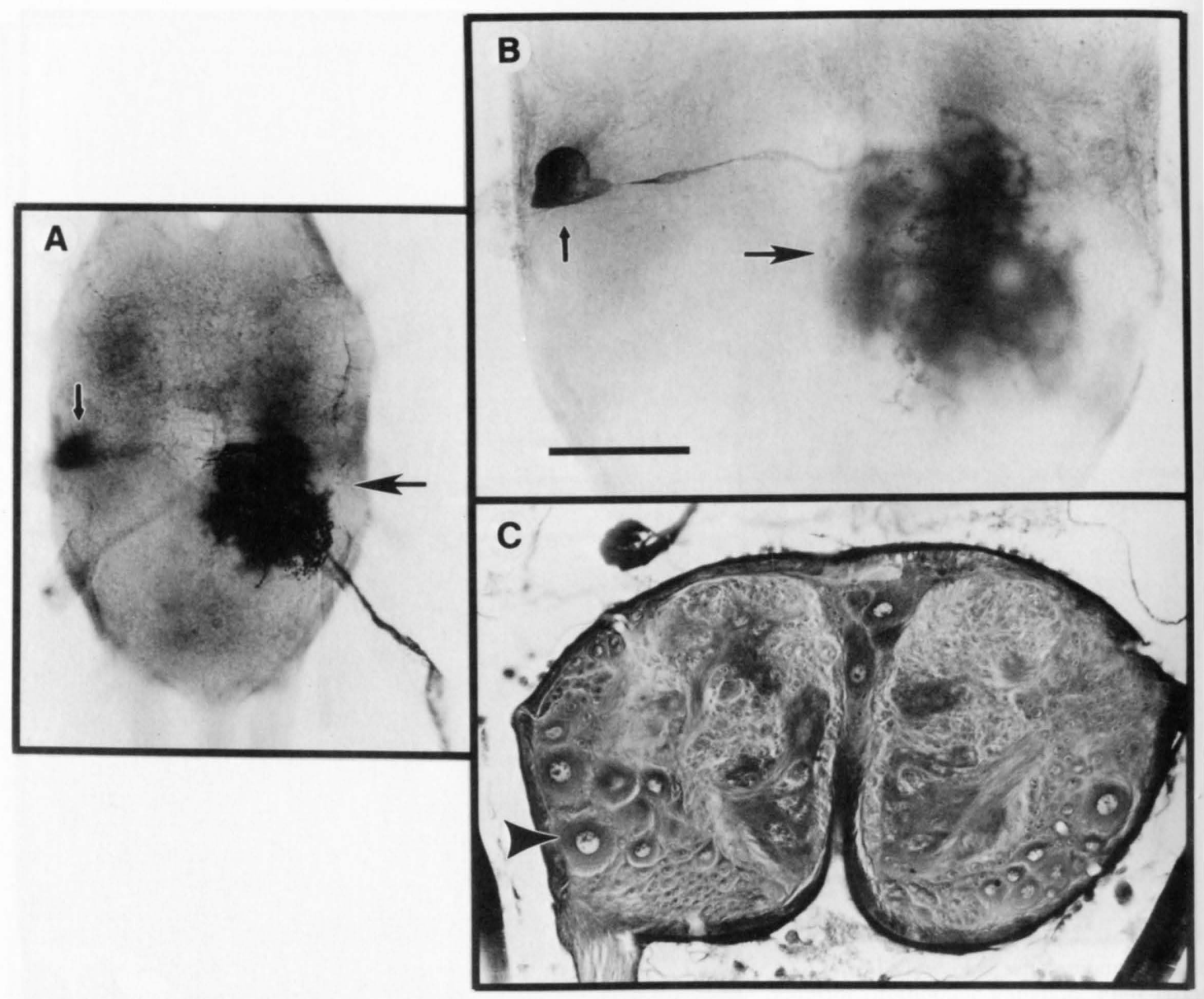

Fig. 4. Photomicrograph of nerve IIIN1C and its associated motoneurons. (A) Dorsal view of the meso-metathoracic ganglia, showing the ipsilateral dendritic fields (large arrow) in the anterior metathoracic ganglia and a single contralateral cell body (small arrow) at a different focal depth. (B) Higher magnification of panel A showing the dorsally located contralateral cell body. (C) An H/E stained cross-section near the fusion of the meso- and metathoracic ganglia showing some of the ipsilateral cell bodies (arrowhead). Calibration bar for (A) $200 \mu \mathrm{m}$; (B, C) $100 \mu \mathrm{m}$.

particularly with deformations of the thorax, such as those performed in evasive flight maneuvers. More specifically, we examined two of the major muscle groups in the thorax, the dorsolongitudinal (depressor) and the dorsoventral (elevator) groups.

The motoneurons that innervate the indirect flight muscles are scattered throughout a considerable region of the pro- and meso-metathoracic ganglia. Generally, the axons of the motoneurons leave the smaller nerves on the ganglia, whereas the larger nerve trunks (such as IINl and IIIN1) primarily convey sensory information from the foreand hindwing bases. In particular, these large nerves appear to contain the sensory information from the thoracic mechanoreceptors on the wings (Orona \& Agee 1987). The axons of the motoneurons identified here emerged from branches on these larger nerve trunks. Motoneurons of nerves IIN1B and IIIN1B innervate the dorsolongitudinal muscles (compare Madsen \& Miller 1987), whereas nerves
IIIN1A and IIIN1C innervate dorsoventral muscles. The overlap between the dendritic fields of motoneurons that control depressor and elevator muscles simplifies the "wiring" architecture required for coordinated neuronal control.

The morphological and physiological characteristics of insect flight motoneurons have been reviewed by Kammer (1985). In general, the cell bodies that lie near the surface of the ganglia make no synaptic contacts and do not generate actively propagated action potentials (Gwilliam \& Burrows 1980 ). The soma gives rise to a single neurite that extends through the neuropil to a relatively large dendritic field (or "integrating zone"). These regions within the dendritic branches have membranes that are excitable electrically and initiate spikes or impulses.

Several generalizations may be made about the organization of the motoneurons that innervate the wing flight muscles in Lepidoptera (see Rind 1983, 


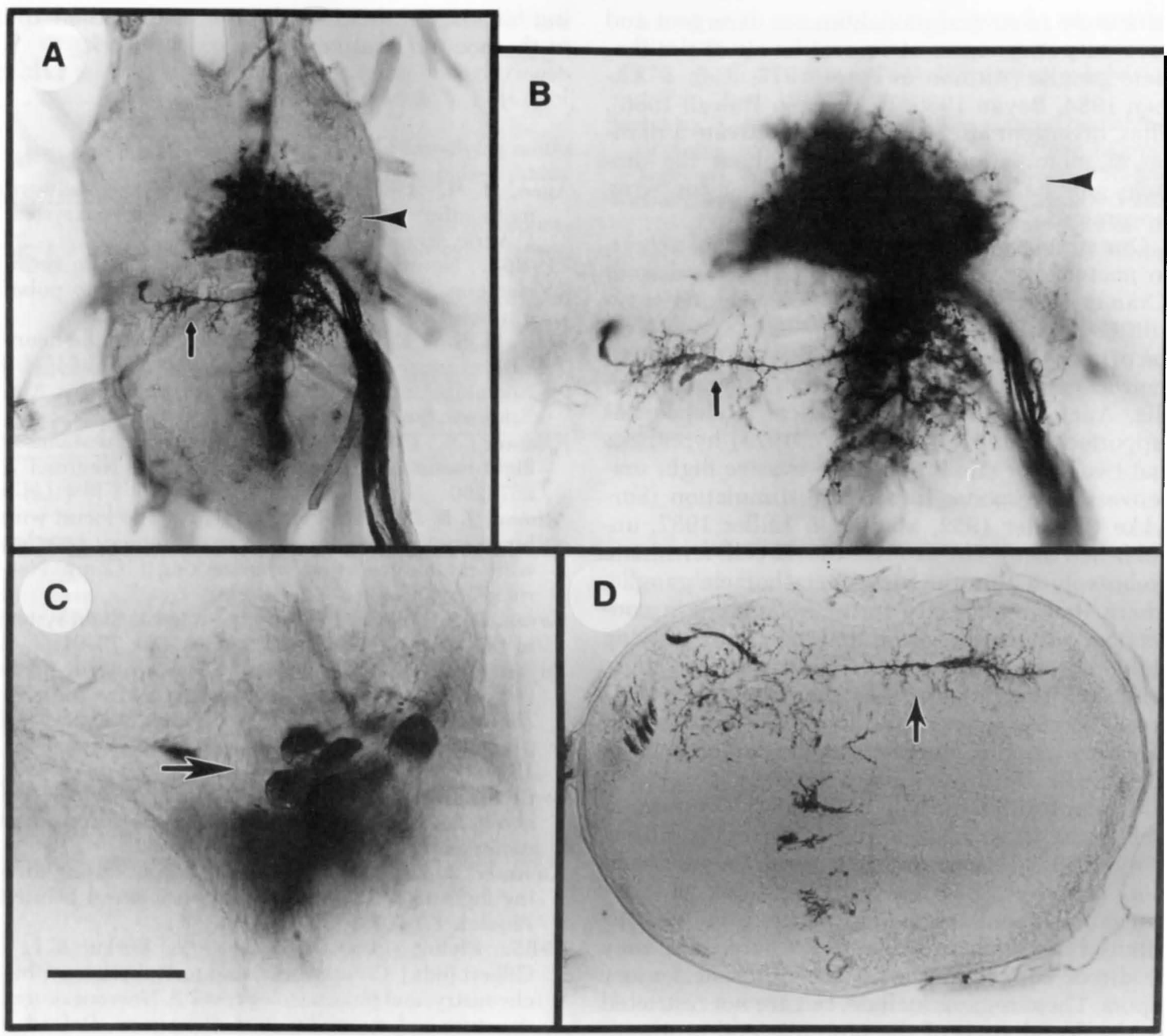

Fig. 5. Photomicrographs of cobalt specimens of the motoneurons in nerve IIIN1B. (A) Dorsal view of the dendritic fields (arrowhead) of the ipsilateral motoneurons and the contralateral soma and neurite (small arrow). (B) Higher magnification of panel A, showing the ipsilateral dendritic plexus (arrowhead) in the posterior meso-, and the contralateral cell body and its neurite (arrow) in the anterior metathoracic ganglia. (C) The five ipsilateral somata (arrow) are located ventrally in the posterior mesothoracic ganglia. (D) Cross-section of the specimen in panel B showing the dorsally located neurite (arrow) of the contralateral cell body. Calibration bar for (A) $200 \mu \mathrm{m}$; (B, C, D) $100 \mu \mathrm{m}$.

Madsen \& Miller 1987). Regardless of the soma location, the entire dendritic fields of these motoneurons tend to be confined to a rather restricted region (ipsi- or contralateral, or both) of the neuropil. The motoneurons of most motor nerves usually have somata both ipsilateral and contralateral to the nerve. Usually, one contralateral motoneuron with its soma and its ipsilateral dendritic field is dorsal within the ganglion. On the other hand, the set of ipsilateral motoneurons also has dendritic fields dorsal, but somata ventral within the ganglion.

Typically, the cell bodies and their respective dendritic fields are confined to a small region of the neuropil, the axon leaving toward the motor nerve trunk at about the same level. Hence, the dendritic fields on the motoneurons are segmented.
Even for a single motoneuron, the dendritic integrating zone is massive and presumably receives a multitude of synaptic inputs. Most identified synapses onto motoneurons appear to be primarily on distal dendritic (and neuritic), rather than on proximal branches or on the soma (Watson et al. 1985). However, previous studies on synaptology have been done primarily with locusts and not Lepidoptera, although some similarities may be expected.

Nonetheless, the segmentation and size of the motoneuronal dendritic fields allow individual neurons to receive much convergent information. In contrast, primary sensory information (acoustic and wing mechanoreceptive) is ascending and distributed widely within the thoracic ganglia and brain of H. zea (Orona \& Agee 1987, unpublished data). Also, it should be noted that descending in- 
terneurons of several modalities are divergent and have output synapses at several levels of the thoracic ganglia (Altman \& Tyrer 1977, Kien \& Altman 1984, Boyan 1985, Reichert \& Rowell 1986). Thus, divergent afferents could co-activate a number of motoneurons located throughout the thoracic ganglia simultaneously, allowing for wing movements.

Our previous studies, as well as those of others, on noctuid moths (Paul 1973: Prodenia eridania (Cramer); Surlykke \& Miller 1982: Agrotis segetum (Denis and Schiffermüler)) have focused on the primary acoustic receptor cells, $\mathrm{Al}$ and $\mathrm{A} 2$, and their axonal terminations within the thoracic ganglia. Anatomical and physiological evidence has supported Roeder's (1962, 1967, 1975) hypothesis that two major circuits mediate evasive flight maneuvers in response to acoustic stimulation (Surlykke \& Miller 1982, Madsen \& Miller 1987, unpublished data). The axons of the A2 cells terminate exclusively within the meso-metathoracic ganglia, where they apparently form monosynaptic connections with motoneurons that innervate the wing flight muscles. On the other hand, another, more complex circuit is formed by the Al cells and their contact on second-order auditory interneurons, located within the thoracic ganglia and the brain (Paul 1974, Boyan \& Fullard 1986).

Axonal terminations of the tympanic nerves, as well as the wing mechanoreceptive inputs (Orona \& Agee 1987), occur throughout the thoracic ganglia. Therefore, because of the motoneuronal organization, there are several locations widely distributed in the thoracic ganglia where there may be direct connections with the different sensory inputs. These regions include, but are not restricted to, the dorsal areas of the posterolateral prothoracic, the anterior and posterior mesothoracic, and the anterior half of the metathoracic ganglion.

Recently, Madsen \& Miller (1987) described the morphological and physiological characteristics of some motoneurons in a noctuid moth (Barathra brassicae L.) and their responses to auditory stimulation. Madsen \& Miller provided additional evidence of monosynaptic influences from A2 cells (but not Al), i.e., that primary acoustic afferents can modulate motoneuronal physiology directly. Moreover, the rhythmicity of motoneuronal spiking even in the absence of acoustic stimuli appears to indicate the activation of central pattern generators. However, it has been asserted (Altman 1982, Reichert \& Rowell 1986) that the presence of sensory mechanoreceptive inputs from the wing bases (Altman \& Tyrer 1977) and their direct physiological interaction with motoneurons (Kien \& Altman 1984) relegate behavior generators to a relatively minor role in flight control. Therefore, more detailed anatomical and physiological studies on lepidopteran motoneurons and wing mechanoreceptors are needed to determine the nature of their interaction with the various sensory modalities. The "identified cell" approach using single-cell mark- ing techniques should help to elucidate their role in the noctuid evasive behavioral network.

\section{References Cited}

Agee, H. R. 1985a. Neurobiology of the bollworm moth: information flow in the central nervous system. J. Agric. Entomol. 2: 277-284.

1985b. Neurobiology of the bollworm moth: neural elements controlling behavioral responses to pulsed ultrasound. J. Agric. Entomol. 2: 345-350.

Agee, H. R. \& E. Orona. 1988. Studies of the neural basis of evasive flight in Heliothis zea (Lepidoptera: Noctuidae): organization of the tympanic nerves. Ann. Entomol. Soc. Am. 81: 977-985.

Altman, J. S. 1982. The role of sensory inputs in insect flight motor pattern generation. Trends Neurosci. 5: 257-260.

Altman, J. S. \& N. M. Tyrer. 1977. The locust wing hinge stretch receptors: I. Primary sensory neurones with enormous central arborizations. J. Comp. Neurol. 172: 409-430.

Boyan, G. S. 1985. Auditory input to the flight system of the locust. J. Comp. Physiol. (A)156: 79-91.

Boyan, G. S. \& J. H. Fullard. 1986. Interneurones responding to sound in the tobacco budworm moth Heliothis virescens (Noctuidae): morphological and physiological characteristics. J. Comp. Physiol. (A) 158: 391-404.

Gwilliam, G. F. \& M. Burrows. 1980. Electrical characteristics of the membrane of an identified insect motor neurone. J. Exp. Biol. 86: 49-62.

Kammer, A. E. 1971. The motor output during turning flight in a hawk moth, Manduca sexta. J. Insect Physiol. 17: 1073-1086.

1985. Flying, pp. 491-552. In G. A. Kerkut \& L. I. Gilbert [eds.], Comprehensive insect physiology, biochemistry, and pharmacology; vol. 5, Nervous system: structure and motor function. Pergamon, Oxford.

Kien, J. \& J. S. Altman. 1984. Descending interneurones from the brain and suboesophageal ganglia and their role in the control of locust behavior. J. Insect Physiol. 30: 59-72.

Madsen, B. M. \& L. A. Miller. 1987. Auditory input to motor neurons of the dorsal longitudinal flight muscles in a noctuid moth (Barathra brassicae L.). J. Comp. Physiol. 160: 23-31.

Orona, E. \& H. R. Agee. 1987. Thoracic mechanoreceptors in the wing bases of Heliothis zea (Lepidoptera: Noctuidae) and their central projections. J. Insect Physiol. 33: 713-721.

1988. An insect model system for the analysis of sensory coding: auditory processing in the noctuid moth Heliothis zea. Proceedings, Symposium on "The Mind: Brain and Learning," Society for the Advancement of Chicanos and Native Americans in Science (SACNAS), September 1986, Pasadena, Calif.

Paul, D. H. 1973. Central projections of the tympanic fibres in noctuid moths. J. Insect Physiol. 19: 17851792.

1974. Responses to acoustic stimulation of thoracic interneurons in noctuid moths. J. Insect Physiol. 20: 2205-2218.

Pringle, J. W. S. 1968. Comparative physiology of the flight motor. Adv. Insect Physiol. 5: 163-227.

Reichert, H. \& C. H. F. Rowell. 1986. Neuronal circuits controlling flight in the locust: how sensory in- 
formation is processed for motor control. Trends Neurosci. 9: 281-283.

Rind, F. C. 1983. The organization of flight motoneurones in the moth, Manduca sexta. J. Exp. Biol. 102: 239-251.

Roeder, K. D. 1962. The behavior of free-flying moths in the presence of artificial ultrasonic pulses. Anim. Behav. 10: 300-304.

1964. Aspects of the noctuid tympanic nerve response having significance in the avoidance of bats. J. Insect Physiol. 10: 529-546

1966. Interneurons of the thoracic nerve cord activated by tympanic nerve fibers in noctuid moths. J. Insect Physiol. 12: 1227-1244.

1967. Turning tendency of moths exposed to ultra- sound while in stationary flight. J. Insect Physiol. 13 873-888.

1975. Neural factors and evitability in insect behavior. J. Exp. Zool. 194: 75-88

Surlykke, A. \& L. A. Miller. 1982. Central branchings of three sensory axons from a moth ear (Agrotis segetum, Noctuidae). J. Insect Physiol. 28: 357-364.

Watson, A. H. D., M. Burrows \& J. P. Hale. 1985. The morphology and ultrastructure of common inhibitory neurones in the thorax of the locust. J. Comp. Neurol. 239: 341-359.

Received for publication 4 December 1987; accepted 7 June 1988 